\title{
Utilization of Sewage Sludge for Production of Electricity using Mediated Salt Bridge Based Dual Chamber Microbial Fuel Cell
}

Anand Parkash*, Shaheen Aziz and Suhail A Soomro

Department of Chemical Engineering, Mehran University of Engineering and Technology, Jamshoro, Pakistan

\begin{abstract}
For developing a feasible world we need to reduce the utilization of fossil fuels and also the pollutant production. These two aims can be fulfilled by treating the waste like sewage sludge. Sewage sludge is a perfect substrate for power generation as they rich in organic substance. This study consolidated bio-cathode with in a dual chamber MFC to generate voltage from sewage sludge $(2 \mathrm{~L})$ at a maximum voltage generated of $2.5 \mathrm{~V}$. The use of bio cathode generates an internal resistance of $36-46 \mathrm{ohm}$, hence yielding maximum voltage generation (2.5 V) from MFC. Saccharomyces cerevisiae sp. was used as biocatalyst. Methylene blue $(10 \mathrm{ml})$ was used a mediator and potassium ferricyanide $(350 \mathrm{ml})$ was used as an oxidizing agent for the conversion of sewage sludge into voltage generation. In this MFC, anode solution was in batch and cathode was in continuous mode of operation under optimum conditions of the operating parameters like $\mathrm{pH}$, oxygen flow rate and substrate concentration.
\end{abstract}

Keywords: Electricity; Sewage sludge; Microbial fuel cell; Biocathode

\section{Introduction}

Today the world is facing many problems of energy crises and global warming, there are also new technologies available in the world to overcome the problems of energy demand and global warming's. The major world energy source is the fossil fuel mostly use now a days. It is predicated that these resources will be depleted in 40-50 years. In addition, it is anticipated that it will damage the environment and cause catastrophic on global environment [1]. These emissions from fossil fuel have alarmed the world community. Microbial Fuel Cell (MFC) is probably the less complicated and one of the most advantage ways of utilizing biomass for replacement of fossil fuels for stationary energy generation. MFC has many advantages regarding environmental pollution and also suitable for power generation. Pakistan has advantages regarding biomass available in large amount. Different researchers also work on different biomass, their blends to decreases the amount of pollution and also decrease the energy crises. When we utilize the biomass it gives good option for decreasing the amount of $\mathrm{CO}_{2}$ and also different types of emissions. In Pakistan agriculture and other waste are increasing, so there is need to be utilize MFCs to reduce it. MFC gives the opportunity to utilize biomass waste with for power generation and to reduce the emissions. The electrochemically active microbes that responsible for substrate oxidation and electron transfer are the key component of MFC, which makes it different from traditional chemical fuel cells in the past decade. The earliest current generation by microorganism was demonstrated by Potter in 1910. However, this finding was not well appreciated until the mid18th century, when it was discovered that microorganisms could transport the electrons gained from cellular metabolism to insoluble minerals (e.g., manganese) in a process termed extracellular electron transfer. During 1990s, researchers have developed various MFC reactors using domestic or industrial wastewater as substrate which greatly accelerated the progress of technology $[2,3]$. In the last decade, numerous research papers on biological wastewater treatment with MFCs have been published. The first generation of MFC is driven by electron mediators. Although mediators can enhance the electron transfer for some microbes, most of the mediators are toxicity and instable, which limit the applications of mediator-assisting MFCs. Comparing traditional bioenergy technologies, the MFC technology has following advantages: (1) broad fuel availability. Nearly all kind of organic matters such as wastewater, sludge and biomass can be utilized as fuel in MFC for electricity production; (2) clean production process and products. A MFC has no substantial intermediary processes, it can convert substrate to electricity directly, which is kind of energy ready for use. There is no second pollution and pollutant production. The off gas is $\mathrm{CO}_{2}$, which can be discharged without further treatment; (3) less sludge production, due to the electricity production. The bacteria growth yield is considerably low compared to that of anaerobic processes; (4) mild operation condition. Unlike anaerobic digestion and other fermentation processes, MFC can be applied in mild condition such as low temperature and low strength wastewaters; (5) no need of aeration. The air cathode MFC could use oxygen directly from air, thus lower the aeration cost; (6) low cost of catalyst. With the development of bio-anode and bio-cathode, microorganisms could sever as efficient catalyst instead of expensive metals; (7) broad applications. MFC was initially designed for wastewater treatment, but with some modifications, MFC could be easily converted to other kind of technologies for special applications such as pollutant removal, hydrogen production and bio production etc. Though promising and has nearly 100 years history, the systematic development of MFC has started only decade ago, MFC is still "young" and has some limitations, such as the performance of the system are far from optimized, the power generation is still low compared with traditional fuel cells; the construction and materials cost are still expensive. The advances in bio cathode research have greatly expanded the application scope of MFCs. It is reasonably expected that with the development of engineering and science, the MFC and its based technologies have the potential to be more promising renewable energy sources for future. MFC is not only

*Corresponding author: Anand Parkash, Department of Chemical Engineering Mehran University of Engineering and Technology, Jamshoro, Pakistan, Tel: 0333796-2266; E-mail: parwani_anand@yahoo.com

Received August 18, 2015; Accepted August 24, 2015; Published August 28 2015

Citation: Parkash A, Aziz S, Soomro SA (2015) Utilization of Sewage Sludge for Production of Electricity using Mediated Salt Bridge Based Dual Chamber Microbial Fuel Cell. J Bioprocess Biotech 5: 251 doi:10.4172/2155-9821.1000251

Copyright: @ 2015 Parkash A. This is an open-access article distributed unde the terms of the Creative Commons Attribution License, which permits unrestricted use, distribution, and reproduction in any medium, provided the original author and source are credited. 
the foundation but also shares common limitations with other MFCbased technologies, thus a better understanding of MFC technology is important and helpful for optimizing all MFC-based technologies. A typical two chamber salt bridge based MFC has two chambers one is cathodic chamber and another anodic chamber and these separated by membrane like salt bridge. In the MFC microbes acting as a biocatalyst, that utilize organic matters and release electrons. In addition, ferricyanide is generally used as electron acceptor, which can enhance power density by 1.5 to 1.8 times. However, toxicity and nonrenewable property of ferricyanide limit its application. There are many specific contaminants (such as nitrate) that can serve as electron acceptors in natural environment. The aim of this research is to generate electricity from sewage sludge using dual chamber MFC in relation to operational parameters like $\mathrm{pH}$, oxygen flow rate, substrate concentration etc. [46].

\section{Materials and Methods}

\section{Substrate collection-sewage sludge}

Sewage sludge $(1000 \mathrm{ml})$, which served as the substrate of the MFC was collected from the hostel of MUET Jamshoro, Pakistan (Table 1).

\section{Fabrication and operation of double chamber MFC}

Salt Bridge-Immersed-Air Cathode MFC consisted of a plastic container of capacity 2 liters which served as the anodic chamber (Figure 1). The anodic compartment contained the substrate and the copper electrodes (6" each). The salt bridge served as an electrolyte in transfer of protons. The cathode was immersed in the salt bridge when it was in molten stage to ensure complete surface contact. The $50 \%$ cathode surface was exposed to atmospheric air.

\section{Salt bridge}

Salt bridge employed here was made with $5 \mathrm{M} \mathrm{NaCl}$ and $10 \%$ Agar. The salt bridge was cast in a PVC pipe $(12 \mathrm{~cm} \times 2 \mathrm{~cm})$. Proper precautions were taken to ensure complete sealing of anodic chamber by means of applying epoxy and wax to ensure anaerobic conditions $[7,8]$.

\section{Cathodic and anodic chamber}

This chamber of the MFC was made up of plastic bottles. Two plastic bottles each of $1000 \mathrm{ml}$ were used for this purpose. The bottle was washed with distilled water and then medium was filled in it [9]. Methylene blue $(10 \mathrm{ml})$, sewage sludge $(2 \mathrm{~L})$ as a sample and Saccharomyces cerevisiae sp. ( $44 \mathrm{~g}$ ) added to it. The sewage sludge was collected from the Hostel from MUET Jamshoro and was stored at room temperature $\left(25 \pm 3^{\circ} \mathrm{C}\right)$.

\section{MFC operation}

Substrate (sewage sludge), was added in anaerobic chamber (anodic chamber) and then it is sealed completely for the creation of anaerobic conditions. In the cathode chamber $2000 \mathrm{ml}\left(\mathrm{H}_{2} \mathrm{O} 650 \mathrm{ml}\right.$ and $\mathrm{C}_{6} \mathrm{~N}_{6} \mathrm{FeK}_{3}$ ) was prepared and put in aerobic chamber (cathodic chamber). Electrodes (copper rods) were inserted in both chambers. Biocatalyst (Saccharomyces cerevisiae) is used in anaerobic chamber (anodic chamber). That digest organic matters present in sewage sludge and release electrons and protons were generated and moved to the cathode from the anodic chamber through salt bridge and by this way voltage was generated. A batch configuration was employed and readings were taken for a period of 20 days. The readings were taken on a daily basis [10-12].

\section{Electrical parameters and measurements}

Digital multimeter (T-33) was used to measure the voltage, which was generated during the experiments. After 20 minutes, readings were recorded for a maximum of 200 minutes.

\section{Results and Discussion}

In the experiment conducted by employing $\mathrm{NaCl}$ and agar based salt bridge, the maximum voltage generated was $2.5 \mathrm{~V}$. All the experiments were performed in salt bridge based MFC. The generated voltage was affected and controlled by the number of factors. For the voltage generation two liters of sewage sludge was utilized in the salt bridge based dual chamber MFC, which generated a maximum voltage of $2.5 \mathrm{~V}$ after 200 minutes (Table 2). After 140 minutes of operation, maximum voltage generated was $2.5 \mathrm{~V}$, and then it shows gradual decrease during the next 60 minutes of operation $[13,14]$. The voltage generation decrease after 140 minutes of operation probably takes place due to the limitation of substrate concentration. It shows that voltage generation was related with the substrate concentration's amount in anodic chamber of MFC. This study also suggested that the utilization if biocatalyst was able to convert the organic materials present in the sewage sludge at their optimum efficiency resulting in the transfer of maximum number of electrons leading to concomitant voltage generation (Figure 2) [13-17].

\section{Factors affecting electricity generation}

Impact of oxygen flow rate on voltage generation: Impact of oxygen flow rate on voltage generation during working of MFC was examined at different oxygen flow rates from 15 to 60 psi yielding in voltage generation between $0.729 \mathrm{~V}$ and $1.00 \mathrm{~V}$ respectively (Figure 3) [18]. These results show that voltage generation enhance as the oxygen flow rate was increased and reached at the maximum of around $2.5 \mathrm{~V}$ at oxygen flow rate of 45 psi before showing decline afterwards. This indicates that at the higher air flow rate, power generation capacity decrease due to the higher rate of oxygen flow rate in air diffused

\begin{tabular}{|c|c|c|c|}
\hline S. No. & Characteristics & Unit & Sewage sludge \\
\hline 1. & $\mathrm{pH}$ & - & 6.7 \\
\hline 2. & Color & - & Greyish \\
\hline 3. & Total Solids & & 1140 \\
\hline 4. & Total Dissolved Solids & & 980 \\
\hline 5. & Suspended Solids & \multirow{2}{*}{ (mg/L) } & 160 \\
\hline 6. & BOD & & 290 \\
\hline 7. & COD & & 945 \\
\hline 8. & Chlorides & & 262 \\
\hline
\end{tabular}

Table 1: Characteristics of sewage sludge.

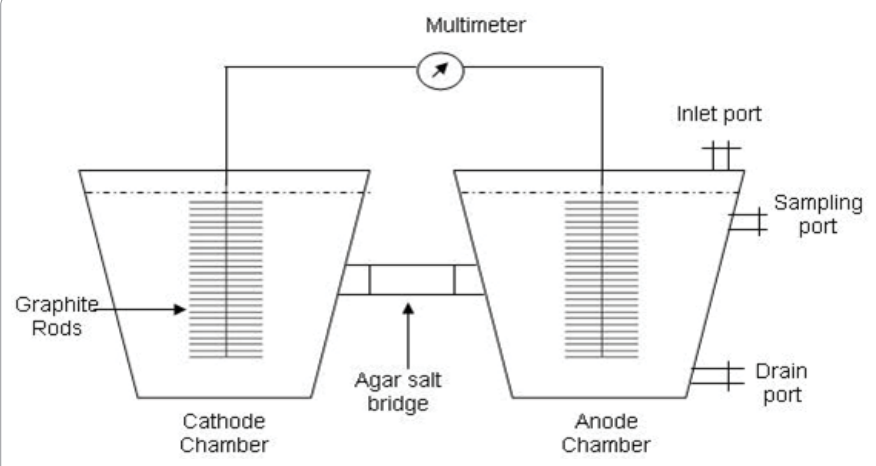

Figure 1: Double chambered MFC. 
Citation: Parkash A, Aziz S, Soomro SA (2015) Utilization of Sewage Sludge for Production of Electricity using Mediated Salt Bridge Based Dual Chamber Microbial Fuel Cell. J Bioprocess Biotech 5: 251 doi:10.4172/2155-9821.1000251

Page 3 of 5

\begin{tabular}{|c|c|}
\hline Time (mins) & Volts (V) \\
\hline 20 & 0.729 \\
\hline 40 & 0.768 \\
\hline 60 & 0.846 \\
\hline 80 & 0.968 \\
\hline 100 & 1.03 \\
\hline 120 & 2.00 \\
\hline 140 & 2.50 \\
\hline 160 & 2.10 \\
\hline 180 & 1.70 \\
\hline 200 & 1.00 \\
\hline
\end{tabular}

Table 2: Voltage generated from sewage sludge.

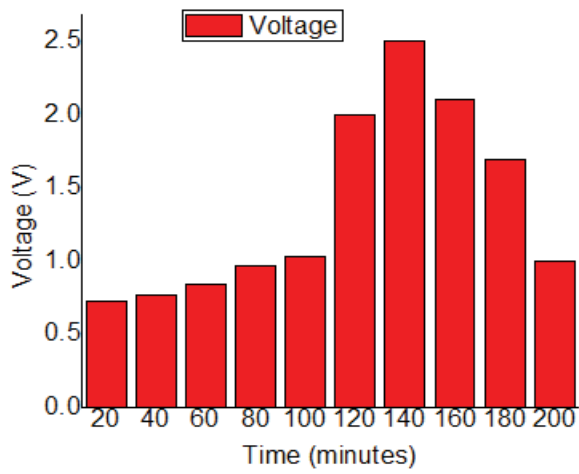

Figure 2: Voltage generation verses time minutes.

down to the vicinity of anode, which probably disturbed the anaerobic microbes living on the anodic surface (Table 3) [19].

\section{Impact of $\mathrm{pH}$ on voltage generation}

$\mathrm{pH}$ is a significant factor that affecting the activity of microbes. Growth and development of microbe's maximum at optimum $\mathrm{pH}$. Figure 4 shows the maximum output of voltage was recorded at $\mathrm{pH} 8.5$. The experiments show that at $\mathrm{pH} 6$ and below, activities of microbes minimum when compared with the result recorded at higher $\mathrm{pH}$. This is by the neutralization of proteins or active sites under acidity. These results demonstrate that there is also impact of $\mathrm{pH}$ on voltage generation using sewage sludge in MFC (Table 4) [20,21].

\section{Impact of substrate concentration on electricity generation}

Power production was observed to increase by enhance in the concentration of substrate (Figure 5) [22]. Starting from about $10 \%$ substrate concentration, generated voltage at $10 \%$ concentration was $0.725 \mathrm{~V}$. At $70 \%$ substrate concentration, voltage was increased up to 2.5 $\mathrm{V}$ and then voltage was decline by decrease in substrate concentration of $100 \%$, the generated voltage at $100 \%$ substrate concentration was 1 $\mathrm{V}$. This is due to the decline in the activity of the microbes owing to various factors such as $\mathrm{pH}$. This was probably due to the reduction in the activity of the enzymes owing to various factors such as $\mathrm{pH}$. This also indicates that higher concentration of the substrate could actually affect the anode performance significantly resulting in simultaneous lesser power production (Table 5) [23,24].

\section{Impact of agar concentration}

In this experiment, maximum voltage generated increased with increase in agar concentration (Figure 6). A maximum of $2.5 \mathrm{~V}$ was obtained with $20 \%$ agar concentration (Table 6). The movement of $\mathrm{O}_{2}$

from higher to lower concentration takes place in cathode was reduced by increased the agar concentration and hence the increase in voltage

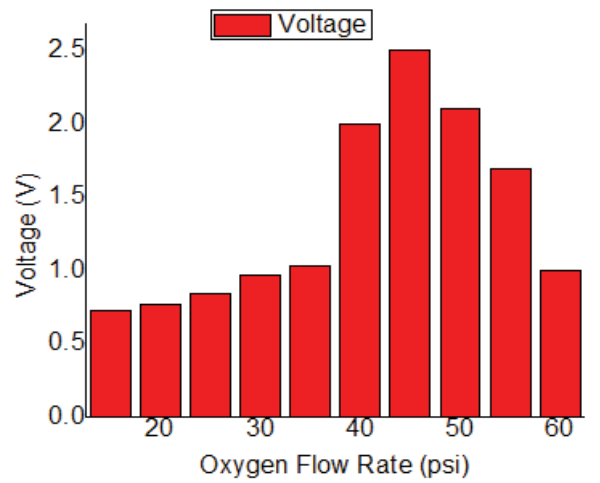

Figure 3: Impact of oxygen flow rate on voltage generation.

\begin{tabular}{|c|c|}
\hline Oxygen Flow Rate (psi) & Volts (V) \\
\hline 15 & 0.729 \\
\hline 20 & 0.768 \\
\hline 25 & 0.846 \\
\hline 30 & 0.968 \\
\hline 35 & 1.03 \\
\hline 40 & 2.00 \\
\hline 45 & 2.50 \\
\hline 50 & 2.10 \\
\hline 50 & 1.70 \\
\hline
\end{tabular}

Table 3: Impact of oxygen flow rate on voltage generation

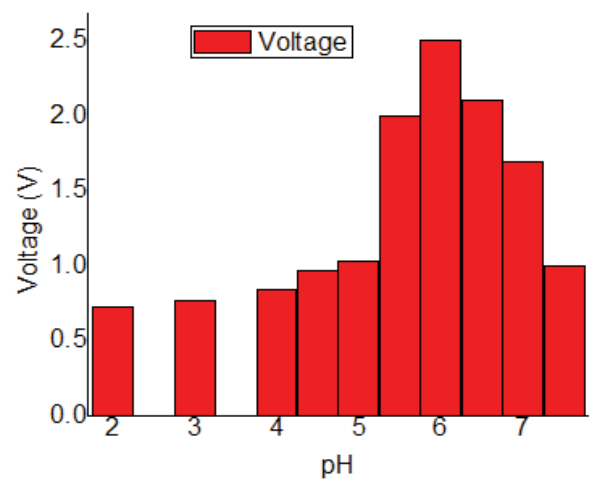

Figure 4: Impact of $\mathrm{pH}$ on voltage generation.

\begin{tabular}{|c|c|}
\hline $\mathbf{p H}$ & Volts $(\mathbf{V})$ \\
\hline 02 & 0.729 \\
\hline 03 & 0.768 \\
\hline 04 & 0.846 \\
\hline 4.5 & 0.968 \\
\hline 05 & 1.03 \\
\hline 5.5 & 2.00 \\
\hline 06 & 2.50 \\
\hline 6.5 & 2.10 \\
\hline 07 & 1.70 \\
\hline 7.5 & 1.00 \\
\hline
\end{tabular}

Table 4: Impact of $\mathrm{pH}$ on voltage generation. 


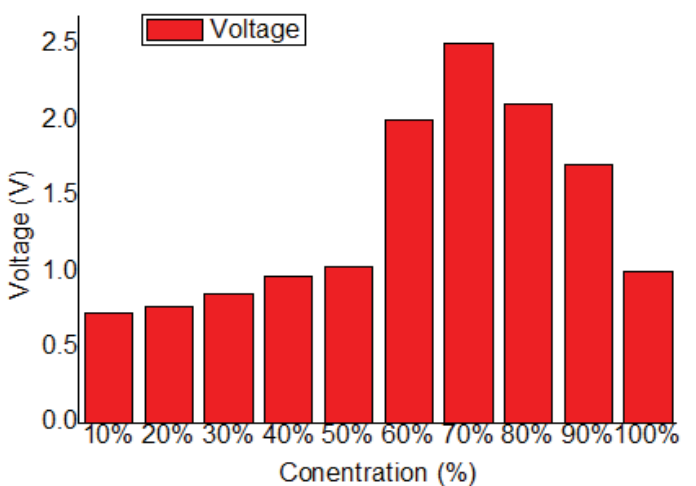

Figure 5: Impact of substrate concentration on voltage generation.

\begin{tabular}{|c|c|}
\hline Concentration (\%) & Volts (V) \\
\hline 10 & 0.729 \\
\hline 20 & 0.768 \\
\hline 30 & 0.846 \\
\hline 40 & 0.968 \\
\hline 50 & 1.03 \\
\hline 60 & 2.00 \\
\hline 70 & 2.50 \\
\hline 80 & 2.10 \\
\hline 100 & 1.70 \\
\hline
\end{tabular}

Table 5: Impact of substrate concentration on voltage generation.

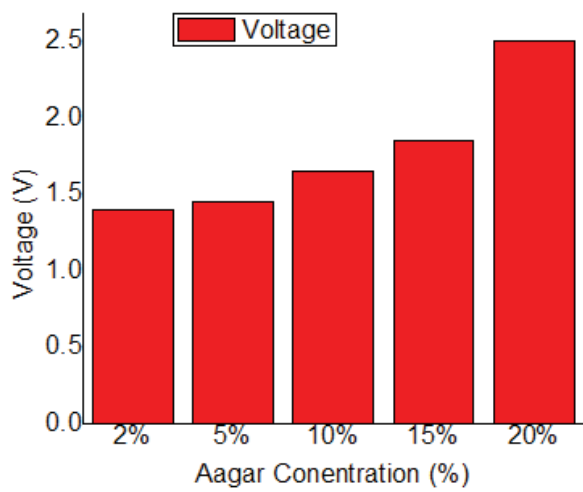

Figure 6: Impact of concentration of agar on voltage generation.

\begin{tabular}{|c|c|}
\hline Agar concentration of salt bridge & Maximum Voltage (V) \\
\hline $2 \%$ & 1.40 \\
\hline $5 \%$ & 1.45 \\
\hline $10 \%$ & 1.65 \\
\hline $15 \%$ & 1.85 \\
\hline $20 \%$ & 2.5 \\
\hline
\end{tabular}

Table 6: Impact of concentration of agar on voltage generation.

generation [25].

\section{Conclusion}

MFC was tested with in the laboratory employing a fixed resistance, which might be thought about to be connected serial with the external resister. Rescale can only be conservative if volumetrically loading rate can be expanded while not decrease in columbic efficiency. Generation of electricity is controlled by factors with proficiency of electron change with in the electrode chamber. Thus, it's clear from the given studies that increasing production of power in MFCs needs innovative flow patterns and conductor orientation that minimizes internal resistance and findings strategies for improved cathode potential. The price of materials utilized for development of MFC is a key issue for application of the technology at the massive scale. Hence, developing a value effective procedure that is environmentally sound and property owing to due utilizing of biodegradable sludge as substrate within the MFCs. In this study double chambered MFC utilizing Saccharomyces cerevisiae was tried for its performance. Different salt bridges were tested. 2.5 volts was maximum voltages, generated by the dual chamber MFC. It was run for 20 days and readings were noted at regular intervals.

\section{Recommendations}

The voltage generated was still low and coupled with a high internal resistance lowered the power generated by the cells. The following are the possible studies and changes that should be established to enhance an MFC's power rating:

1. The electrical conductivity of the MFC fuel solution should be enhanced to levels that do not affect the microbial community in the sewage/waste as well as to levels that lower the cell's internal resistance to acceptable levels.

2. Studies on voltage and resistance changes should also be carried out at an hourly or half-hour basis to get a better view of the variation of voltage with time.

3. Studies should be carried out to establish the most appropriate $\mathrm{C} / \mathrm{N}$ ratio that gives off the highest electrical voltage. Further studies can also be made through digestion of several biodegradable materials to establish which materials will give the highest voltage from the cell.

4. Applying of genetic engineering in the development of strains of bacteria that will be highly adaptive, efficient in the breakdown of the bio material as well as have a high affinity for a variety of bio material.

5. Up scaling of the MFC to larger treatment volumes like septic tanks and industrial food processing waste ponds and with further development, designs should be made that incorporate MFC into waste water treatment plants.

\section{Acknowledgements}

The author wish to express his sincere thanks for the lab facilities provided for this work in the Department of Chemical Engineering, Mehran University of Engineering and Technology, Jamshoro, Pakistan.

\section{References}

1. Chang IS, Kim BH, Lovitt RW, Bang JS (2001) Effect of CO partial pressure on cell-recycled continuous CO fermentation by Eubacterium limosum KIST612. Process Biochem 37: 411-421.

2. Chang IS, Jang JK, Gil GC, Kim M, Kim HJ, et al. (2004) Continuous determination of biochemical oxygen demand using microbial fuel cell type biosensor. Biosens Bioelectron 19: 607-613.

3. Chang IS, Moon H, Jang JK, Kim BH (2005) Improvement of a microbial fuel cell performance as a BOD sensor using respiratory inhibitors. Biosens Bioelectron 20: 1856-1859.

4. Cheng X, Shi Z, Glass N, Zhang L, Zhang J, et al. (2004) A review of PEM hydrogen fuel cell contamination: Impacts, mechanisms, and mitigation. $J$ Power Sources 305: 1280-1283. 
Citation: Parkash A, Aziz S, Soomro SA (2015) Utilization of Sewage Sludge for Production of Electricity using Mediated Salt Bridge Based Dual Chamber Microbial Fuel Cell. J Bioprocess Biotech 5: 251 doi:10.4172/2155-9821.1000251

Page 5 of 5

5. Gong M, Liu X, Trembly J, Johnson C (2007) Sulfur-tolerant anode materials for solid oxide fuel cell application. J Power Sources 168: 289-298.

6. Kim IS, Chae KJ, Choi MJ, Verstraete W (2008) Microbial fuel cells: recent advances, bacterial communities and application beyond electricity generation. Environ Eng Res 13: 51-65

7. Kim JR, Min B, Logan BE (2005) Evaluation of procedures to acclimate a microbial fuel cell for electricity production. Appl Microbiol Biotechnol 68: 23-30.

8. Lee J, Phung NT, Chang IS, Kim BH, Sung HC (2003) Use of acetate for enrichment of electrochemically active microorganisms and their 16S rDNA analyses. FEMS Microbiol Lett 223: 185-191.

9. Liu H, Cheng S, Logan BE (2005) Production of electricity from acetate or butyrate using a single-chamber microbial fuel cell. Environ Sci Technol 39 658-662.

10. Pham TH, Jang JK, Chang IS, Kim BH (2008) Improvement of cathode reaction of a mediatorless microbial fuel cell. J Microbiol Biotechnol 14: 324-329.

11. Ragauskas AJ, Williams CK, Davison BH, Britovsek G, Cairney J, et al. (2006) The path forward for biofuels and biomaterials. Science 311: 484-489.

12. Gil GC Chang IS, Kim BH, Kim M, Jang JK et al. (2003) Operational parameters affecting the performannce of a mediator-less microbial fuel cell. Biosens Bioelectron 18: 327-334.

13. Song $C$ (2008) Fuel processing for low-temperature and high-temperature fue cells: Challenges and opportunities for sustainable development in the $21 \mathrm{st}$ century. Catal Today 77: 17-49.

14. Aelterman P, Rabaey K, Pham HT, Boon N, Verstraete W (2006) Continuous electricity generation at high voltages and currents using stacked microbial fuel cells. Environ Sci Technol 40: 3388-3394.

15. He Z, Minteer SD, Angenent LT (2005) Electricity generation from artificial wastewater using an upflow microbial fuel cell. Environ Sci Technol 39: 5262-5267.
16. Liu H, Logan BE (2004) Electricity generation using an air-cathode single chamber microbial fuel cell in the presence and absence of a proton exchange membrane. Environ Sci Technol 38: 4040-4046.

17. Rabaey K, Clauwaert P, Aelterman P, Verstraete W (2005) Tubular microbial fuel cells for efficient electricity generation. Environ Sci Technol 39: 8077-8082.

18. Schröder U, Niessen J, Scholz F (2003) A generation of microbial fuel cells with current outputs boosted by more than one order of magnitude. Angew Chem Int Ed Engl 42: 2880-2883.

19. You S, Zhao Q, Zhang J (2006) A microbial fuel cell using permanganate as a cathodic electron acceptor J Power Sources 162: 1409-1415.

20. You S, Zhao Q, Zhang J (2006) A graphite-granule membrane-less tubular aircathode microbial fuel cell for power generation under continuously operational conditions. J Power Sources 173: 172-177.

21. Jiansheng $H$, Ping $Y$, Yong $G$, Zhang $K$ (2011) Electricity generation during wastewater treatment: An approach using an AFB-MFC for alcohol distillery wastewater. Desalination 276: 373-378.

22. Oh ST, Kim JR, Premier GC, Lee TH, Kim C, et al. (2010) Sustainable wastewater treatment: how might microbial fuel cells contribute. Biotechnol Adv 28: 871-881.

23. Du Z, Li H, Gu T (2007) A state of the art review on microbial fuel cells: A promising technology for wastewater treatment and bioenergy. Biotechnol Adv 25: $464-482$.

24. Zhao F, Harnisch F, Schroder U, Scholz F, Bogdanoff P, et al. (2006) Application of pyrolyzed iron (II) phthalocyanine and CoTMPP based oxygen reduction catalysts as cathode materials in microbial fuel cells. Electrochem commun 7: 1405-1410.

25. You SJ (2005) Identification of denitrifying bacteria diversity in an activated sludge system by using nitrite reductase genes. Biotechnol Lett 27: 1477-1482. 